BMJ Paediatrics Open

\title{
Substandard medicines: a greater problem than counterfeit medicines?
}

Helen M Sammons, ${ }^{1,2}$ Imti Choonara ${ }^{1}$

To cite: Sammons HM, Choonara I. Substandard medicines: a greater problem than counterfeit medicines? BMJ Paediatrics Open 2017;1:e000007. doi:10.1136/ bmjpo-2017-000007

Received 14 March 2017 Revised 20 April 2017 Accepted 21 April 2017

\section{CrossMark}

${ }^{1}$ Academic Unit of Child Health, University of Nottingham, Derbyshire Children's Hospital, Derby, UK

${ }^{2}$ Paediatrics, North Devon District Hospital, Barnstaple, UK

Correspondence to Emeritus Professor Imti Choonara, Academic Unit of Child Health, University of Nottingham, Derbyshire Children's Hospital, Derby DE22 3NE, UK; Imti.Choonara@ nottingham.ac.uk
Substandard medicines are medicines which have failed to pass the quality measurements and standards set for them. ${ }^{1}$ They should be distinguished from counterfeit (falsified) medicines which are deliberately and fraudulently mislabelled. Combining the two together however is not helpful. They are different problems that require different solutions. Substandard and counterfeit medicines are a widespread problem in low-income and lower-middle-income countries. A systematic review showed that the median prevalence of substandard and counterfeit medicines was $28.5 \%{ }^{1}$ This ranged from $11 \%$ to $48 \%$ in individual studies. The 15 studies were all limited to antimicrobial drugs, with the majority (13) including antimalarials. Only 2 of the 15 studies within the systematic review differentiated between substandard and counterfeit medicines. Both studies involved antimalarial drugs in South East Asia. They both found that counterfeit medicines were a greater problem than substandard medicines. The biggest problem in relation to the quality of the medicines tested was an inadequate amount of the active ingredient.

\section{HIGH-INCOME COUNTRIES}

Although the prevalence of substandard medicines in high-income countries is unknown, studies in both the UK and Canada show it is a significant issue. ${ }^{23}$ Contamination and stability issues were the major problems in Canada, whereas contamination is the major problem in the UK. There were 74 cases of contamination of medicinal products within the UK over an 11-year period ${ }^{2}$ and 139 incidents in Canada over a 9-year period. ${ }^{3}$ Counterfeit medicines were a minor problem, both in Canada and the UK. An increasing number of substandard medicines have been identified in both Canada and the UK over time, although this may be due to improved detection by regulatory agencies. It is important to note that substandard medicines were not restricted to the manufacturers for generic medicines, but involved all the major pharmaceutical companies in both Canada and the UK.

The clinical impact of substandard medicines is unknown. Contaminated drugs were however responsible for more than 120 deaths at a single hospital in Pakistan. ${ }^{4}$ Additionally, more than 700 individuals developed a fungal infection following the use of contaminated methylprednisolone in the USA, associated with at least 61 deaths. ${ }^{5}$ These events suggest that for high-income countries, substandard medicines may be a greater problem clinically than counterfeit medicines. This may also be the situation in lower-income and lower-middle-income countries as illustrated by a study of the Medicines Quality Database (MQDB). ${ }^{6} \mathrm{MQDB}$ is an online database that documents medicines tested for quality in selected countries in Africa, Asia and South America. ${ }^{6}$ A recent study of over 15000 samples identified 848 samples (5.6\%) as being of poor quality. ${ }^{6}$ The majority of the failed samples were substandard (767, $90.4 \%)$. The remaining $81(9.6 \%)$ were counterfeit. Additional evidence suggesting that substandard medicines are a greater problem than counterfeit medicines is provided by the problems associated with diethylene glycol.

\section{DIETHYLENE GLYCOL}

Diethylene glycol is an industrial solvent. It was used as a solvent for sulfanilamide in the USA in the 1930s. There were over 100 deaths including 34 children. This tragedy resulted in legislation in the USA to ensure that formulations of medicines were tested for safety.

Diethylene glycol poisoning results in gastrointestinal problems initially-nausea, vomiting, diarrhoea, abdominal pain and anorexia. Subsequently, a wide variety of symptoms may occur including weakness, lethargy, malaise, fever and restlessness. Central nervous system depression, seizures, metabolic acidosis, liver failure and acute renal failure can also develop. 
It has been used fraudulently in counterfeit medicines, which have resulted in the deaths of over 100 children. ${ }^{7}$ It has also been found as a contaminant in substandard medicines and this has resulted in the deaths of over 200 children in Haiti, Nigeria and India. ${ }^{7}$ There have also been cases of contamination of products in Spain and the USA. It is worth noting that more children have died from substandard medicines contaminated with diethylene glycol than counterfeit medicines where diethylene glycol has been used as a solvent.

\section{HOW MANY SUBSTANDARD MEDICINES ARE ACCEPTABLE?}

No system is perfect. It is inevitable that there will be substandard medicines just as there are other substandard products. The question however is 'What degree of substandard medicines are acceptable?' Because a substandard medicine can result in a fatal outcome for the patient, the responsibility for minimising the occurrence of substandard medicines should be greater than that on the manufacturer of a non-essential consumer product. Data from the UK and Canada, alongside recent events in both Pakistan and the USA, suggest that substandard medicines are a significant problem and are not restricted to pharmaceutical products from middle-income countries or companies specialising in the manufacture of generic medicines. The data from Canada and the UK show that all companies are associated with substandard medicines. The pharmaceutical industry however needs to accept their responsibility for trying to ensure that substandard medicines are an infrequent occurrence.

\section{RECOGNISING SUBSTANDARD MEDICINES}

Health professionals need to be aware that medicines like any other product may be substandard. Counterfeit medicines may be recognised by spelling mistakes in the packaging. Recognising substandard medicines is more difficult. The possibility of a substandard medicine should be considered if: a patient fails to respond to treatment; if several patients who have received the same batch of a particular drug fail to respond to treatment; if an unusual adverse drug reaction occurs. For medicines administered parenterally, unusual appearance or smell should raise suspicion that the medicine may be contaminated. Because of the difficulties in recognising substandard medicines, it is essential that the pharmaceutical industry does its utmost to minimise substandard medicines.

Contributors Both authors contributed to the paper and approved the final version.

Competing interests IC is an Editor for the journal.

Patient consent Not applicable.

Provenance and peer review Commissioned; externally peer reviewed.

Open Access This is an Open Access article distributed in accordance with the Creative Commons Attribution Non Commercial (CC BY-NC 4.0) license, which permits others to distribute, remix, adapt, build upon this work non-commercially, and license their derivative works on different terms, provided the original work is properly cited and the use is non-commercial. See: http://creativecommons.org/ licenses/by-nc/4.0/

(C) Article author(s) (or their employer(s) unless otherwise stated in the text of the article) 2017. All rights reserved. No commercial use is permitted unless otherwise expressly granted.

\section{REFERENCES}

1. Almuzaini T, Choonara I, Sammons H. Substandard and counterfeit medicines: a systematic review of the literature. BMJ Open 2013;3:e002923.

2. Almuzaini T, Sammons H, Choonara I. Substandard and falsified medicines in the UK: a retrospective review of drug alerts (20012011). BMJ Open 2013;3:e002924.

3. Almuzaini T, Sammons H, Choonara I. Quality of medicines in Canada: a retrospective review of risk communication documents (2005-2013). BMJ Open 2014;4:e006088.

4. Arie S. Contaminated drugs are held responsible for 120 deaths in Pakistan. BMJ 2012;344:e951.

5. Smith RM, Schaefer MK, Kainer MA, et al. Fungal infections associated with contaminated methylprednisolone injections. $\mathrm{N}$ Engl $J$ Med 2013;368:1598-609.

6. Hajjou M, Krech L, Lane-Barlow C, et al. Monitoring the quality of medicines: results from Africa, Asia, and South America. Am J Trop Med Hyg 2015;92(6 Suppl):68-74.

7. Alkahtani S, Sammons H, Choonara I. Epidemics of acute renal failure in children (diethylene glycol toxicity). Arch Dis Child 2010;95:1062-4. 